\title{
STUDI KELAYAKAN DAN PERSYARATAN RUANG SHALAT BERDASARKAN SYARAT RUANG SHALAT DALAM ISLAM STUDI KASUS MASJID AL-MARKAZ AL-LSLAMI DI KABUPATEN MAROS
}

\author{
Ansarullah $^{1}$, Muhammad Tayeb ${ }^{2}$ \\ ${ }^{1}$ Jurusan Arsitektur, Fakultas Teknik, Universitas Muslim Indonesia \\ ${ }^{2}$ Prodi Arsitektur, Fakultas Teknik, Universitas Khairun Ternate
}

\begin{abstract}
Abstrak
Dengan perkembangan akan kebutuhan manusia baik itu kebutuhan yang hubungan antara sesama manusia juga kebutuhan akan hubungan manusia dengan pencipta-Nya. Dengan demikian perlu adanya kegiatan untuk mengkaji ruang shalat sebagai fungsi utama ditinjau dari syarat ruang peribadatan Islam. Kajian ini dilakukan pada Masjid Al Markaz Al Islami yang merupakan masjid utama, menampung berbagai macam kegiatan keagamaan dan sosial. Dengan adanya kompeksitas ruang, diharapkan ketentuan mendasar yang berkaitan dengan fungsi utama tidak terabaikan, seperti kesucian tempat, arah kiblat, pemisahan gender, pengaturan shaf, mihrab dan mimbar, dan perangkat pelengkap ruang shalat lainnya. Ada sedikit kekurangan pada aspek kesucian tempat yaitu batas antara area suci dan najis yang diinterpretasikan dengan memberikan perbedaan warna dan tekstur lantai, dan ketinggiannya, secara visual masih belum cukup ditangkap oleh para jamaah. Begitu juga dengan aspek pengaturan shaf yang menjadi sedikit lebih renggang karena keberadaan permadani dengan motif yang bersekat-sekat dan akustik ruang yang masih terdengar gaung, dengan jarak yang masih bisa ditoleransi.
\end{abstract}

Kata kunci: ruang shalat, arsitektur masjid

\begin{abstract}
With the development of human needs will either need relationships between fellow humans also need the human relationship with their Creator. Thus the need for action to review the main prayer hall as a function in terms of the requirements of Islamic worship space. The study was conducted at the Masjid Al Markaz Al Islami which is the main mosque, accommodating a variety of religious and social activities. Given the complexity of the space, is expected to fundamental provisions relating to the main function is not neglected, such as the sanctity of the place, the direction of Qibla, gender segregation, setting rows, mihrab and minbar , and other complementary devices prayer halls. There is a bit of a shortage on the aspects of the sanctity of the place that is the boundary between sacred and unclean areas are interpreted to provide the difference in color and texture of the floor, and height, visually still not sufficiently captured by the pilgrims. So also with aspects of setting rows are being a little more tenuous because of the existence of a rug with a pattern that sectional and acoustic space that still sounds echo, with a range that can be tolerated
\end{abstract}

Keywords: Prayer room, Mosque architecture

\section{PENDAhuluan}

Menurut Munawwir Kata masjid berasal dari bahasa Arab; Sajada-yasjudu-sujudan, dari verba itu lahirlah kata masjidun \orang Arab telah terbiasa menggunakan kata masjidun berarti masjadun- yaitu tempat yang digunakan oleh seseorang atau sekelompok orang untuk sujud kepada Allah Swt.

Masjid adalah rumah Allah, tempat peribadatan umat Islam yang sangat dimuliakan dan dijaga kesuciannya. Tentunya ruang-ruang yang tersusun didalamnya juga menyesuaikan prinsipprinsip desain masjid yang mendukung untuk mewadahi segala bentuk kegiatan peribadatan umat Islam. Pada dasarnya masjid memiliki fungsi utama yaitu sebagai tempat sujud umat Islam, yang artinya ruang shalat menjadi ruang inti yang wajib ada dalam bangunan masjid. Selain sebagai tempat sujud (ibadah maghdhah), masjid juga berperan sebagai pusat kehidupan komunitas muslim pada masa itu.

Namun seiring perkembangan zaman dengan kemajuan teknologi modern, masjid kini dapat dibangun sedemikian rupa dengan adanya eksplorasi ruang, elemen, serta bentuk dan gaya arsitektural sebagai pemenuh kebutuhan dari berbagai kegiatan peribadatan Islam baik hubungan manusia dengan manusia maupun manusia dengan pencipta-Nya. Perlahan kecenderungan ini mampu mengkaburkan orientasi masyarakat dalam memandang sebuah masjid. Maka timbullah keluhan dari masyarakat baik dari segi fisik maupun visual yang terjadi akibat dari prinsip yang tidak terwadahi dalam karyanya. Beberapa diantaranya seperti bentuk dan pola tata ruang yang kurang tersusun rapi, penghawaan yang tidak nyaman, akustik yang tidak rapi dan fasilitas yang tidak 
memadai, terawat, dan terolah dengan baik akan mengurangi daya tarik dan mempengaruhi kekhusyukan terhadap jamaah masjid. Selain itu pengaruh terhadap privasi atau pemisahan ruang antara jamaah pria dan wanita dan kemudahan atau kepraktisan perawatan masjid itu sendiri akan berdampak pula pada kenyamanan terkait kebersihan dan kesuciannya. Salah satu yang dapat diambil contoh dalam penelitian ini adalah Masjid Al Markaz Al Islami, merupakan masjid yang mampu menampung berbagai macam kegiatan keagamaan dan sosial. Dengan adanya kompeksitas ruang, diharapkan ketentuan mendasar yang berkaitan dengan fungsi utama tidak terabaikan, seperti kesucian tempat, arah kiblat, pemisahan gender, pengaturan shaf, mihrab dan mimbar, dan perangkat pelengkap ruang shalat lainnya sehingga nantinya berbagai permasalah yang ada dapat dipelajari dan dijadikan acuan oleh masyarakat dalam membangun masjid.

Aspek pengamatan ini ditentukan dari tinjauan pustaka maupun penelitian yang terkait. Berkaitan dengan hal tersebut, maka unit-unit yang diamati mengenai ruang shalat meliputi:

a. Kesucian tempat

Kesucian tempat diuraikan dari salah satu elemen pembentuk ruang, pembatas bawah (lantai), selain itu pengamatan terhadap alur sirkulasinya yang berpotensi mengkaburkan batas suci dan najis. b. Menghadap kiblat

Mencari posisi kiblat terhadap arah hadap bangunan dengan software kiblat locator.

c. Pemisahan gender

Adanya zonafikasi dalam ruang shalat berdasarkan gender. Namun zonafikasi tersebut bersifat fleksibel karena berbagai macam kebutuhan ruang dari berbagai kegiatan yang ditampung. Zonafikasi tersebut dipertegas dengan dua hal yaitu:

Hijab, yang terbuat dari kayu dan bersisfat portable sehingga bisa dipindah-pindah, fleksibel mengikuti pola dari zonafikasinya.

d. Pengaturan shaf

Adanya elemen ruang yang dapat mengarahkan rapat dan lurusnya shaf shalat dari pola lantai atau karpet.

e. Mihrab dan mimbar

Mihrab sebagai petunjuk arah kiblat, penghemat barisan shaf, dan pintu alternatif bagi ta'mir merupakan hal yang dibutuhkan dalam ruang shalat berskala nasional. Begitu juga mimbar sebagai tempat khutbah yang merupakan salah satu rangkaian kegiatan shalat jum'at yang wajib diadakan di masjid.

f. Perangkat pelengkap ruang shalat

Ada hal lain di luar ruang shalat namun masih berkaitan kebutuhannya yaitu:

- Pengeras suara, sebagai sarana mempermudah jalannya shalat berjamaah.

- Rak mushaf, penataannya yang mudah dijangkau dalam ruang shalat dengan luasan tersebut.
- Perangkat untuk bersuci, sebagai sarana membantu menjaga kesucian ruang shalat.

- Petunjuk waktu shalat, pengadaan jam di tempattempat yang terlihat.

Penelitian ini menggunakan metode deskriptif analitik, dengan teknik analisa data kualitatif, yaitu melakukan observasi terhadap ruang shalat kemudian gambaran objek tersebut dijelaskan beserta analisanya berdasarkan syarat ruang peribadatan Islam.

\section{ISI PENELITIAN}

2.1. Analisis Kondisi Eksisting Masjid AlMarkaz Al Islami

Al Markaz Al Islami berlokasi di Jl. Jenderal Sudirman, Kabupaten Maros Sulawesi Selatan. Secara fisik, luas bangunan dan fasilitas penunjang adalah $5261 \mathrm{~m}^{2}$, dengan rincian ruang shalat lantai satu $3280 \mathrm{~m}^{2}$. Bangunan Masjid terdiri dari tiga lantai. (Gambar 1)

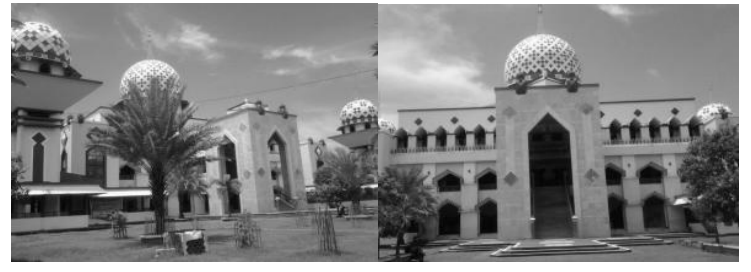

Gambar 1. Masjid Al Markaz Al Islami Maros

Ruang shalat memiliki tempat yang paling luas daripada ruang-ruang lainnya. Ruang shalat mewadahi beberapa kegiatan peribadatan baik maghdhah maupun ghairu maghdhah.

Banyaknya kegiatan yang ditampung membuat susunan ruang di dalam ruang shalat menjadi lebih fleksibel, namum tetap harus terkelola berdasarkan syarat ruang peribadatan Islam karena mewadahi aktivitas ibadah maghdhah yang menjadi fungsi utama dan sangat perlu untuk diperhatikan syaratsyaratnya. Jadi prinsip ini penting untuk diinterpretasikan ke dalam penataan ruang shalat dan ruang-ruang terkait sebelum mereka bentuk dan estetikanya.

Beberapa prinsip tersebut adalah kesucian tempat, menghadap kiblat, pengaturan shaf, pemisahan gender, mihrab dan mimbar, dan perangkat pelengkap ruang shalat.

\subsection{Berdasarkan Kesucian Tempat}

Berdasarkan hasil pengamatan, ruang shalat memiliki berbagai macam cara yang dilakukan untuk menginterpretasikan kesucian tempat dalam bangunannya. Ditinjau dari elemen pembatas bawah.Warna dan tekstur.

Pada area suci, yaitu ruang shalat dan teras bagian dalam, menggunakan lantai berbahan granit berukuran $120 \times 60 \mathrm{~cm}$ agar pemasangan lantai di ruang shalat tersebut lebih cepat, dan dapat 
digunakan dalam jangka waktu yang lama. (Gambar 2)

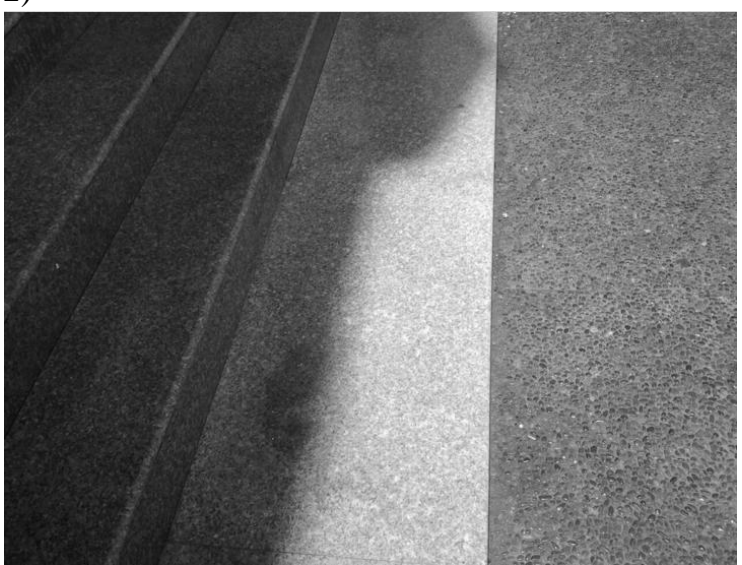

Gambar 2. Perbedaan Warna dan Tekstur Pada Teras

Cirinya bercorak khas batu granit dan marmer berwarna abu-abu dengan tekstur halus dan mengkilap. Penggunaan marmer tersebut juga dapat membuat ruang shalat terasa sejuk.

Pada area najis, yaitu di teras masjid bagian luar diberikan lantai keramik berukuran $30 \times 30 \mathrm{~cm}$. Keramik tersebut berbeda dengan marmer yang digunakan pada lantai suci. Warna merah menjadi faktor pembeda dengan lantai suci. Pemasangan menyilang pada keramik bertujuan agar tidak membahayakan jamaah ketika masih memakai alas kaki.

Begitu juga pada main entrance, lantai suci sama seperti sebelumnya, berbahan mamer, berwarna abuabu, dan bertekstur halus dan mengkilat. Sedangkan untuk lantai najis, menggunakan keramik biasa yang bertekstur kasar, berwarna merah, disusun berpola. (Gambar 3)

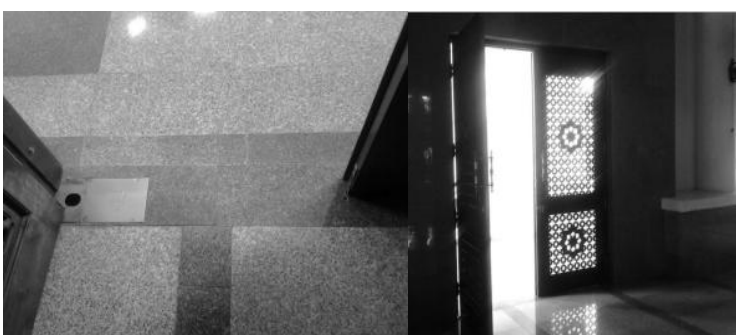

Gambar 3. Perbedaan Warna dan Tekstur Pada Main Entrance

Main entrance merupakan area rekreatif ditengah beratap terbuka sehingga sangat memungkinkan lantai najis pada area ini terkena cuaca panas dan dingin serta hujan secara langsung dalam waktu yang lama. Oleh karena itu pada area ini diberikan keramik kasar berukuran lebih kecil yaitu seluas 20x20 cm untuk mencegah terjadinya kerusakan lantai.

\subsection{Level Ketinggian}

Perbedaan jenis dan tekstur lantai agaknya belum memberikan pesan secara tajam sehingga untuk lebih mempertegas batas tersebut, diperlukan tambahan eksplorasi desain yang lebih terhadap elemen ini dengan cara lain yaitu membedakan level ketinggiannya dengan cara memberi sedikit kenaikan setinggi $1 \mathrm{~cm}$ dari lantai najis ke lantai suci pada teras masjid.

Berdasarkan pengamatan, timbul suatu kasus yaitu kurang hati-hatinya jamaah dalam menjaga kesucian teras masjid, terkadang alas kaki yang berada di lantai teras najis terseret ke lantai teras suci sehingga diberikan tambahan penegas batas tersebut berupa penanda bertuliskan 'batas suci'

Pada main entrance terdapat perbedaan level ketinggian $20 \mathrm{~cm}$. Ketinggian ini dibuat untuk mencegah masuknya air dari lantai najis ke lantai suci karena area rekreatif dengan atap terbuka ini sangat rawan terjadi genangan air dan cipratan yang besar baik dari air kolam maupun air hujan sehingga untuk mencegah terjadinya kontaminasi pada lantai suci, area ini diturunkan dan diberikan saluran pembuangan air. Ketinggian tersebut pastinya dapat menahan alas kaki yang berada di lantai najis agar tidak memasuki lantai suci teras masjid. Hal ini juga dapat memudahkan jamaah untuk 'membaca' batas suci sehingga tidak ada keraguan terhadap kesucian area tersebut. (Gambar 4).

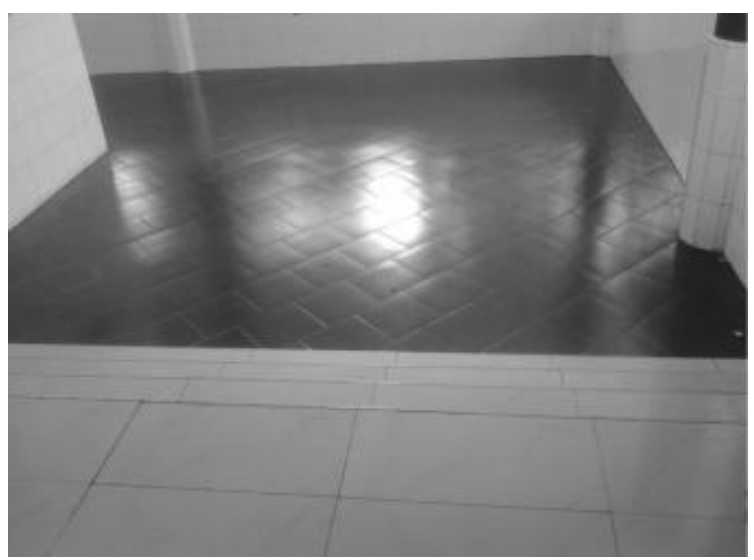

Gambar 4. Perbedaan Level Ketinggian Pada Teras dan Main Entrance

\subsection{Ditinjau Dari Alur Sirkulasi}

Alur sirkulasi berikut terjadi karena susunan dari pencapaian hingga akses ruang shalat tersebar merata di semua sisi. Mulai dari tangga masuk, tempat wudhu, dan pintu masuk. Tidak ada pemisahan gender yang jelas terkait sirkulasi di sekitar ruang shalat, kecuali sirkulasi dari tangga yang mengarah pada tempat wudhu pria dan wanita.

Alur sirkulasi jamaah wanita terdiri menjadi tiga macam, yaitu bagi jamaah wanita yang sudah suci, belum suci, dan batal suci. Jika sudah bersuci, dari halaman parkir menaiki tangga menuju lantai 1 kemudian langsung memasuki ruang shalat melewati teras. Namun jika belum suci menuruni tangga dalam menuju tempat wudhu untuk bersuci terlebih dahulu, atau dari halaman parkir menuruni tangga 
menuju basement (tempat wudhu) kemudian menaiki tangga dalam menuju lantai 1 atau keluar kembali ke halaman parkir menaiki tangga luar menuju lantai 1. (Gambar 5)

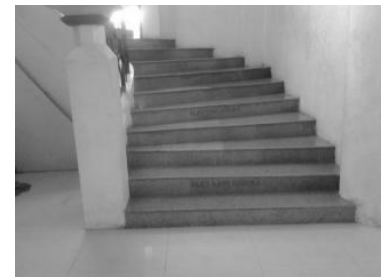

Bagian Barat

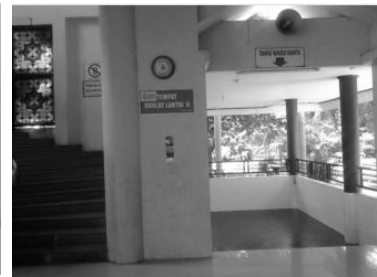

Bagian Timur
Gambar 5. Alur Sirkulasi Jamaah Wanita

Tempat wudhu dan kamar mandi pria dibuat lebih luas daripada wanita agar dapat menampung jamaah pria yang jumlahnya memang lebih banyak daripada wanita ketika berkunjung ke masjid. Banyaknya pintu menuju tempat wudhu dan kamar mandi pria agar tidak berdesakan saat jamaah membludak sehingga sulit masuk atau keluar.

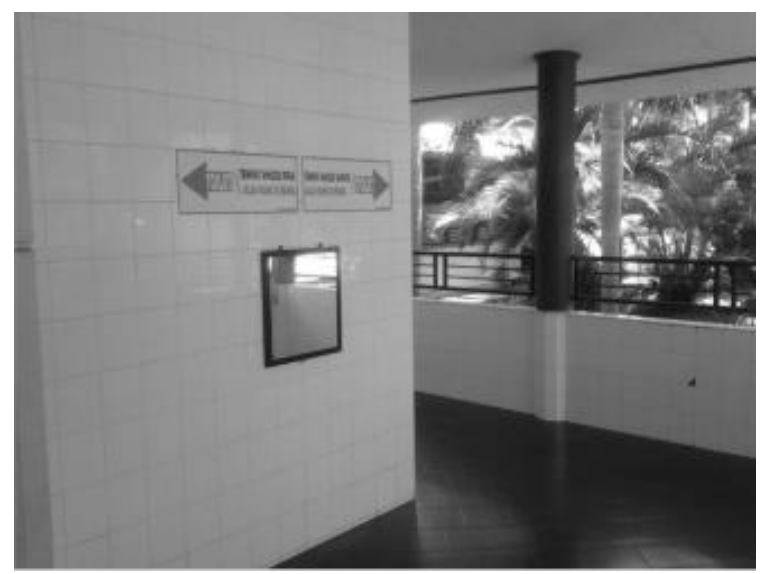

Gambar 6. Alur Sirkulasi Jamaah Pria

Alur sirkulasi jamaan pria terdiri dari tiga macam, yaitu dari halaman parkir menaiki tangga menuju lantai 1, dari halaman parkir langsung memasuki bordes tangga dalam (split level) untuk kemudian menuruni tangga menuju lantai dasar (tempat wudhu) atau menaiki tangga menuju lantai 1, dan dari halaman parkir menuruni anak tangga menuju (tempat wudhu).

\subsection{Berdasarkan Arah Kiblat}

Arah kiblat tidak hanya sekedar arah Barat, namun jika dilihat dari titik koordinatnya, Ka'bah memiliki latitude 21.42258 dan longitude 39.826163. Sedangkan Masjid Al-Akbar Surabaya memiliki titik koordinat dengan latitude -5.015174 , dan longitude 119.572512.

Berdasarkan pengamatan, Masjid Al Markaz Al Islami didirikan langsung menghadap kiblat sehingga mudah untuk diketahui arah kiblatnya terhadap ka'bah dalam aplikasi tersebut. Hanya memutar $90^{\circ}$ gambar layout yang didapatkan dari
Badan Perencanaan dan Pengembangan kearah Barat.

\subsection{Berdasarkan Pemisahan Gender}

Pemisahan yang dimaksud diinterpretasikan dengan memberikan pembatas fisik atau visual antara ruang shalat pria dan wanita. Pemisahan ini membentuk zonafikasi yang fleksibel dalam ruang shalat, namun posisi jamaah wanita tetap konsisten berada di belakang imam dan jamaah pria.

Hal ini dipengaruhi oleh dimensi ruang yang luas dan beraneka macam kegiatan keagamaan yang ditampung seperti shalat ied, shalat jum'at, kajian keagamaan, akad nikah, dan sebagainya.

Faktor tersebut juga mempengaruhi pemilihan bentuk hijab yang sesuai dengan keadaan tersebut sehingga pembatas vertikal yang dipakai adalah hijab yang bersifat portable. Hijab ruang shalat wanita terbuat dari segmen- segmen metal dan viber berukuran $120 \times 300 \mathrm{~cm}$.

Kelebihan hijab seperti ini adalah mudah dibawa dan dapat dipindah- pindah. Namun kekurangannya adalah hijab dengan posisi seperti ini dapat mengganggu view dalam ruang shalat karena terkesan adanya ruangan dalam ruangan.
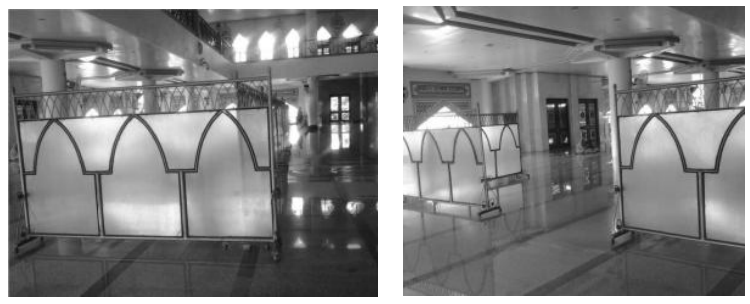

Gambar 7. Hijab dan Ruang Shalat Wanita

Pemisahan gender tidak hanya berlaku di ruang shalat, namun juga di ruang lainnya seperti tempat wudhu dan kamar mandi. Zonafikasi yang terbentuk di tempat ini terjadi karena adanya penyebaran sirkulasi yang merata bagi jamaah pria dan wanita, selain karena besarnya dimensi ruang shalat.

Berdasarkan hasil pengamatan, tidak ada pemisahan sirkulasi bagi jamaah pria maupun wanita baik di dalam maupun di luar ruang shalat dan pintu masuk sebagai akses utama manuju ruang shalat. Jumlah jamaah wanita yang datang ke masjid lebih sedikit dibandingkan dengan jumlah jamaah pria sehingga alur sirkulasi lebih fleksibel ke berbagai arah. Selasar memiliki lebar $6 \mathrm{~m}$ dan akses yang dilewati jamaah pria maupun wanita dari tempat wudhu menuju ruang shalat menjadi satu. begitupun tangga menuju tempat wudhu pria dan wanita belum terpisah .

Pintu masuk ruang shalat yang tidak dipisah bagi jamaah pria dan wanita menimbulkan kekhawatiran tersendiri dalam menjaga wudhu selama berada didalamnya. Namun, ternyata pintu tersebut didesain dengan ukuran lebar 3 meter, untuk meminimalisir terjadinya desakan antara jamaah satu dengan lainnya saat melewatinya. 


\subsection{Pengaturan Shaf}

Pengaturan shaf di ruang shalat dimulai dari pembatas bawah yaitu pola lantai dan karpet. Pola lantai granit sudah membentuk barisan shaf berdasarkan garis natnya. (Gambar 8)

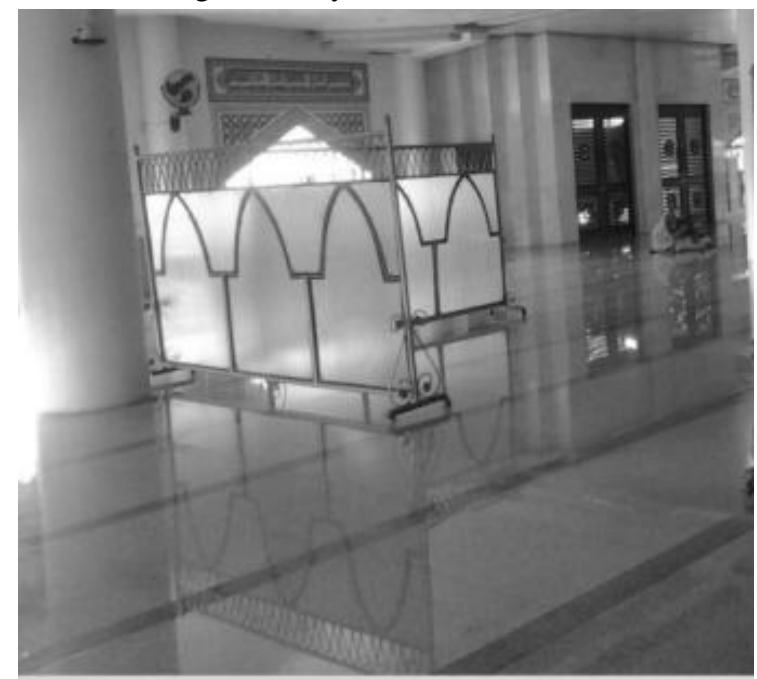

Gambar 8. Pola Lantai Marmer Ruang Shalat

Jika diteliti berdasarkan standar ukuran tubuh manusia Indonesia dengan tinggi, wanita 155-165 $\mathrm{cm}$, dan pria $165-175 \mathrm{~cm}$, ukuran tersebut sudah cukup untuk membuat barisan shaf jamaah rapat dan lurus.

Namun, seiring berjalannya waktu ada penambahan elemen interior berupa karpet yang berwarna hijau dan bermotif floral dan garis-garis vertikal sebagai alas shalat. Motif tersebut secara tidak langsung menggiring beberapa para jamaah untuk tidak merapatkan shaf karena ‘terkapling' oleh motif sekat tersebut. (Gambar 9)

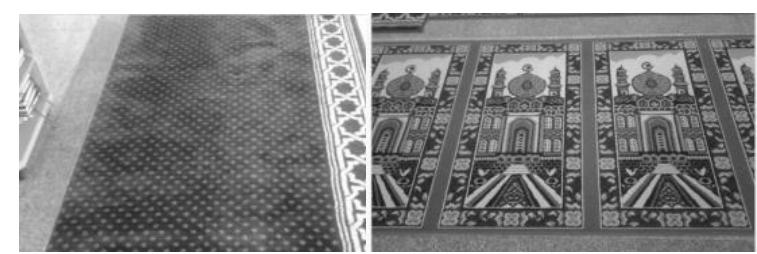

Gambar 9. Permadani Untuk Alas Shalat

Pada dasarnya lebar tempat sujud hanya butuh tempat selebar $120 \mathrm{~cm}$. Namun agar tidak terjadi senggolan antara barisan depan dan belakang yang mengganggu saat shalat, maka diberi tambahan 30 $\mathrm{cm}$ sebagai jarak amannya. Sedangkan untuk panjang disesuaikan dengan luas ruangan dan kebutuhan. Oleh karena itu pemilihan elemen interior yang berhubungan dengan syarat peribadatan dan ruangannya juga harus ada pertimbangan yang cermat.

\subsection{Mihrab dan Mimbar}

Di tempat shalat masjid Al-Markaz Al Islami terdapat point of interest yang menonjol di dalam ruangan yaitu mihrab dan mimbar. Penggunaan mihrab yang dilakukan oleh tim perancangan masjid sudah ideal. Terdapat pintu tembusan di ruang mihrab menuju ruangan lain dan ruang imam. Mihrab ini juga bisa menjadi jalan pintas bagi penceramah yang hendak melakukan khutbah jum'at. (Gambar 10)

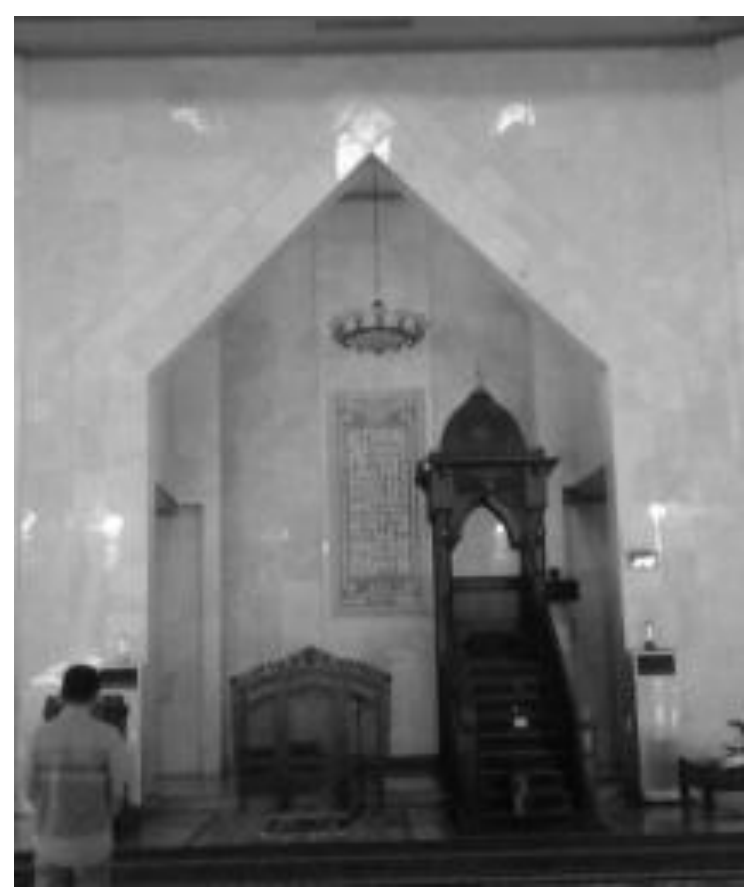

Gambar 10. Mihrab

Berdasarkan hasil pengamatan, bagian depan ruang shalat masjid disediakan space selebar $4 \mathrm{~m}$ untuk meletakkan mimbar-mimbar ini. Mimbar biasanya diletakkan di depan jamaah, di dalam atau di sebelah kanan mihrab, digunakan saat ceramah agama atau acara-acara kajian Islam. Mimbar dibuat dengan ketinggian 3 meter agar dapat dilihat dari jarak terjauh dalam ruang shalat sehingga mendukung kemantapan keberadaan pembicara. (Gambar 11)
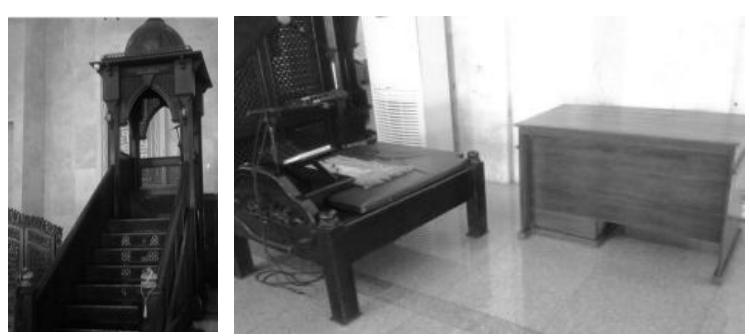

Gambar 11. Mimbar

\subsection{Pelengkap Ruang Shalat}

Pelengkap ruang shalat biasanya berupa ruangruang lain selain ruang shalat terkait ruang shalat seperti: tempat wudhu, kamar mandi, dan gudang. Begitu juga elemen interiornya/perabot yang hampir ada di semua masjid sebagai sarana untuk mendukung kegiatan beribadah para jamaah seperti: 
rak mushaf, petunjuk waktu shalat, microphone, dan speaker.

\section{Tempat Wudhu}

Jika diamati dari alur aktivitas manusia pada ruang tersebut mulai dari melepas alas kaki, menuju ruang transisi, kemudian memasuki tempat wudhu atau kamar mandi. Setelah dari kamar mandi atau tempat wudhu dapat kembali ke ruang transisi untuk kemudian langsung memasuki ruang shalat melalui tangga dan teras masjid atau keluar kembali. (Gambar 12)

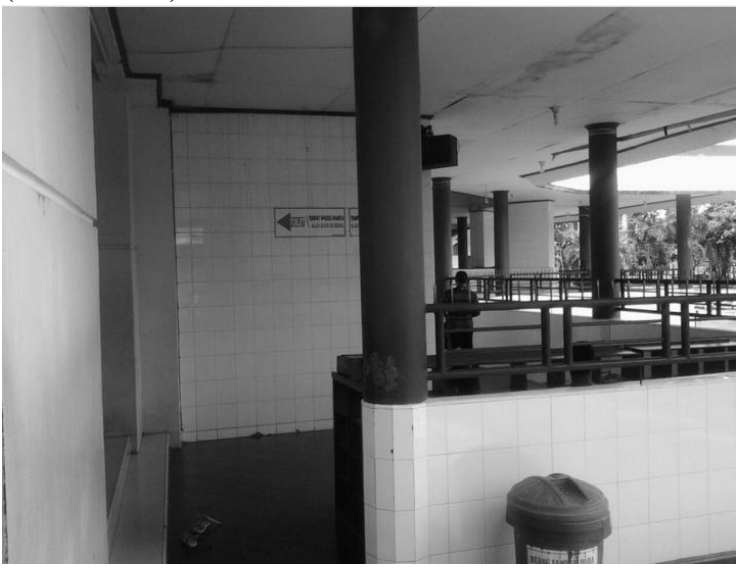

Gambar 12. Pembatas Ruang di Tempat Wudhu

Sama halnya dengan tempat wudhu wanita, untuk menjaga kesucian lantai tempat wudhu pria, pintu masuk yang berbatasan langsung dengan ruang luar dipertegas dengan berbagai cara. Pembatas yang jelas antara area luar (najis) dengan area transisi (suci) ditunjukkan dengan perbedaan level ketinggiannya. Pembatas dari area transisi menuju tempat wudhu dibedakan dengan pemberian kolam air, sedangkan untuk kamar mandi dibedakan dengan level ketinggian pembatas bawah dan keset. (Gambar 13)

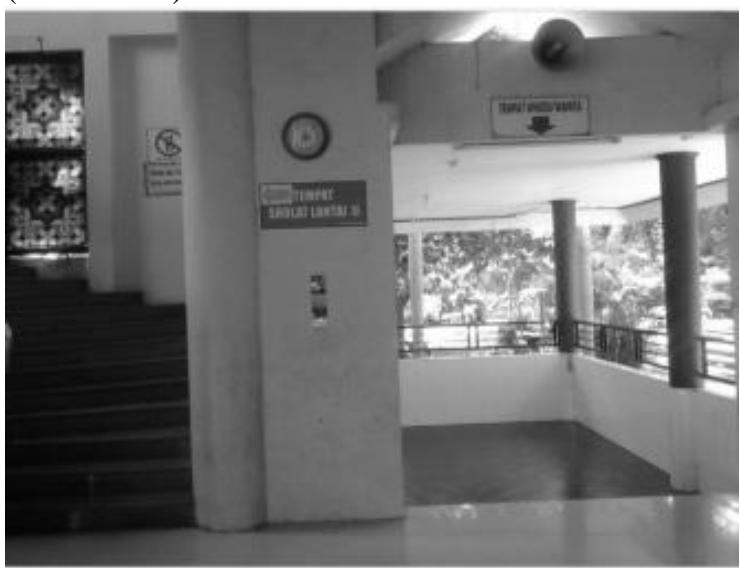

Gambar 13. Pembatas Ruang di Tempat Wudhu Wanita

Begitu pula dengan rak penyimpanan mushaf yang berada di tepi dinding, jaraknya menyesuaikan keberadaan rak lainnya pada kolom sehingga mudah dijangkau oleh jama'ah masjid yang ingin membacanya. Satu rak mushaf terdiri dari dua tingkat, masing-masing berisi maksimal empat puluh mushaf.

\section{Rak Mushaf}

Rak penyimpanan mushaf tersebut disusun menyebar di berbagai titik dalam ruang shalat, jadi tidak berkumpul di satu titik. Titik-titik tersebut berada pada kolom-kolom masjid agar tidak mengganggu sirkulasi. Jarak antar kolom satu dengan lainnya 6 meter, kecuali area bebas kolom yang berada di bawah kubah.

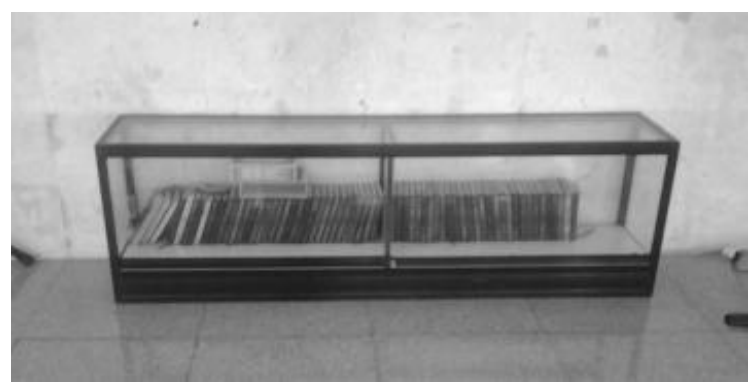

Gambar 14. Rak Mushaf di Ruang Shalat

\section{Petunjuk Waktu Shalat}

Sebagai penanda waktu shalat diperlukan adanya alat yang dapat memudahkan jamaah dari arah manapun untuk mengenali waktu shalat karena hal itu merupakan salah satu syarat sah shalat. Ada tiga macam alat yang dapat digunakan untuk mengetahui waktu shalat yaitu jam dan speaker masjid. (Gambar 15)

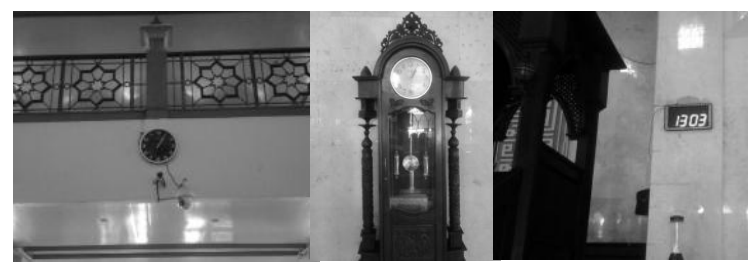

Gambar 15. Petunjuk Waktu Shalat

\section{Microphone dan Speaker}

Speaker yang terdapat di dalam ruang masjid ada sebanyak 4 buah, dipasang di dinding masjid setinggi 3 meter, dengan jarak yang berbeda-beda antar speaker satu dengan lainnya. Jarak ini ditentukan oleh kekuatan gelombang suara yang dikeluarkan oleh masing-masing speaker. (Gambar 16)
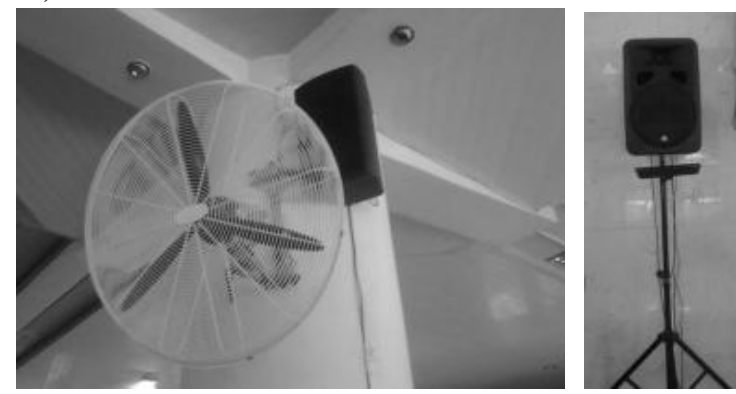

Gambar 16. Pengeras Suara di Ruang Shalat 
Di samping penataan speaker baik dari jenis dan jarak perletakannya, untuk mendapatkan akustik ruang yang rapi perlu ada dukungan dari elemenelemen ruang yang ikut andil terhadap gelombang suara yang ditimbulkan sehingga untuk menghindari gaung dalam ruang shalat tersebut. (Gambar 17)

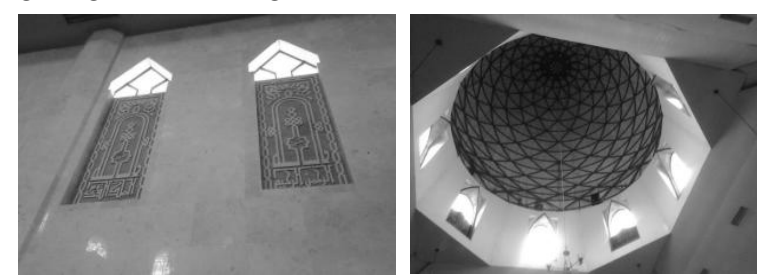

Gambar 17. Peredam Suara di Ruang Shalat

\section{KESIMPULAN}

Dari hasil penelitian, ada beberapa hal yang menjadi koreksi kesesuaiannya terhadap syarat ruang peribadatan Islam. Jika ditinjau dari kesucian tempat, batas area suci dan najis sudah dirancang dengan baik. Namun ada beberapa sisi yang timbul kekurangan akibat perilaku manusia sehingga perlu tambahan penanda di lokasi tersebut, baik di teras maupun tempat wudhu.

Banyak akses alternatif dari ruang luar menuju ruang shalat untuk kemudahan menjaga kesucian.

Di ruang shalat sudah ada pemisahan gender. Akan tetapi, berbagai macam kegiatan keagamaan yang diwadahi, pembatas tersebut bersifat fleksibel tergantung dari jumlah jamaah yang datang sehingga pembatas tersebut bersifat portable.

Ruang shalat memiliki akustik yang kurang baik. Pemberian speaker di beberapa titik serta peredam bagian atas berupa kubah belum diselubungi oleh peredam suara, bagian samping (dinding) didesain datar sehingga terjadi pantulan suara. Demikian pula bagian bawah merupakan granit yang masih berpotensi memberikan efek gaung.

\section{DAFTAR PUSTAKA}

- Ahmad Warson Munawwir, (Al-Munawwir Kamus Arab-Indonesia, Yogjakarta: Pondok Pesantren Krapyak, p. 650,1984.

- Al-Qaradhawi, Yusuf. Tuntunan Membangun Masjid. Jakarta: Gema Insani Press, 2000.

- Bahar, M. Arsyad. Evaluasi Terhadap Aspek Kebersihan dan Kesucian Dalam Perancangan Arsitektur Masjid. Journal of Islamic Architecture. Universiti Kebangsaan Malaysia. Malaysia.

- Husain, Huri Y. 2011. Fikih Masjid, 2012. Kemenag Bantul. Cara Mudah dan Sederhana Menentukan Arah Kiblat yang Benar, Jakarta: Pustaka Al-Kautsar, 2012.

- Nugroho, F. Karpet Sajadah Merusak Shaf, 2011.

- www.kemenagbantul.go.id (Diakses pada hari Jum'at, tanggal 5 Februari 2016).

- www.edisipertama.wordpress.com (Diakses pada hari Jum'at, tanggal 3 Februari 2016). 